\title{
TITLE:
}

\section{Immature male gibbons produce female-specific songs.}

\section{$\operatorname{AUTHOR}(\mathrm{S}):$}

Koda, Hiroki; Oyakawa, Chisako; Kato, Akemi; Shimizu, Daisuke; Rizaldi; Koyama, Yasuhiro; Hasegawa, Satoshi

\section{CITATION:}

Koda, Hiroki ... [et al]. Immature male gibbons produce female-specific songs.. Primates; journal of primatology 2013, 55(1): 13-17

\section{ISSUE DATE:}

2013-10-25

URL:

http://hdl.handle.net/2433/196935

\section{RIGHT:}

The final publication is available at Springer via http://dx.doi.org/10.1007/s10329-0130390-2; この論文は著者最終稿です。内容が印刷版と異なることがありますので、引用 の際には出版社版をご確認ご利用ください。This is the Accepted Author Manuscript. Please cite only the published version. 
News and Perspectives to Primates

\section{Immature male gibbons produce female-} specific songs

Hiroki Koda $^{\text {a*}}$, Chisako Oyakawa ${ }^{\text {ab }}$, Akemi Kato ${ }^{\text {a }}$, Daisuke Shimizu ${ }^{\text {cd }}$, Rizaldie,

Yasuhiro Koyama', Satoshi Hasegawag

aprimate Research Institute, Kyoto University, Japan

${ }^{\mathrm{b}}$ Graduate School of Agricultural Science, Tohoku University, Japan

`Japan Monkey Center, Japan

${ }^{\mathrm{d}}$ Graduate School of Science, Kyoto University, Japan

eDepartment of Biology, Faculty of Science and Mathematics, Andalas University

${ }^{\mathrm{f}}$ NHK Enterprise Co. Ltd., Japan

gInfinity Co. Ltd., Japan

Keywords: Gibbon songs; sexual differentiation; sexual maturation; song development 
2/Koda et al. Video evidences for great calls by immature male gibbon

\section{Abstract}

Gibbons are apes that are well known to produce characteristic species-specific loud calls, referred to as "songs." Of particular interest is the sex specificity observed in "great calls" of female songs. However, little is known about the development of this call. While great calls have been observed to be given by female gibbons of different ages, they have never been recorded from males. Here, we report 2 observations of immature male gibbons from 2 different species, wild Hylobates agilis and captive $H$. lar, spontaneously singing female-specific great calls. Based on the video clips, we conclude that immature males also have the potential of producing great calls. Our observations lead us to propose a new hypothesis for the development of sexual differentiation in the songs of gibbons and bear on the general issue of sex-specific behaviors in primates.

Key words: Gibbon songs; sex specificity; sexual maturation; sexual differentiation 
3/Koda et al. Video evidences for great calls by immature male gibbon

Gibbons are apes that are well-known to produce characteristic species-specific loud calls, which are referred to as “songs” (Preuschoft et al. 1984; Marshall and Sugardjito 1986). Currently, 4 genera of gibbons (Hylobates, Symphalangus, Nomascus, and Bunopithecus) have been identified, with this taxon occupying a wide range of habitats in southeast Asia (Lappan and Whittaker 2009). Like bird song, gibbon songs exhibit sequential structuring of single vocal utterances (“notes”), with both species and sexual specificity (Haimoff 1984). Vocal characteristics have been used to assess the systematic relationships among gibbon species (Family Hylobatidae) and to reconstruct their phylogeny and evolution (Marshall and Marshall 1976; Brockelman and Schilling 1984; Marshall and Sugardjito 1986; Geissmann 2002). It has been proposed that the production of gibbon songs is inherited, rather than involving a learning process (Brockelman and Schilling 1984).

Of particular interest is the sex-specificity of gibbon songs. A part of femalespecific songs, termed the "great call," is an approximately 10 -sec phase that contains a more complicated species-specific acoustic pattern compared to male songs (Geissmann 2002). Great calls are typically given during vocal duets between a mated pair and have been hypothesized to strengthen the pair bond. Sex-specificity in songs is particularly noticeable in Hylobates and Nomascus (Geissmann 2002), with males and females in these 2 genera producing overlapping vocal notes, elements, and songs. In Hylobates, the female-specific acoustic patterns of great calls are substantially different in form compared to male song, i.e., none of the elements in great calls are ever produced by males (Haimoff 1984; Geissmann 2002). Since newborn and infant female gibbons do not give great calls nor other song types, great calls are expected to be acquired later in life. Because strong sexual dimorphism like gibbon songs is rarely observed in primate 
4/Koda et al. Video evidences for great calls by immature male gibbon

vocalizations (Geissmann 2002), the developmental process of sexual differentiation in vocal signals is of special interest for the issue of vocal development in nonhuman primates. However, little is known about the developmental process of primate speciesspecific songs. In one study of Nomascus, a genus that differs from Hylobates, the acoustic features of great calls given by immature females were reported to change gradually during the early stages of song development (Merker and Cox 1999). Great calls were hypothesized to be a kind of female-specific behavior that emerges at the appropriate developmental stage of female sexual maturation. In contrast, great calls have never been observed at any developmental stage of male maturation. Consequently, the sexual differentiation of gibbon songs is expected to arise through this type of acoustic developmental process.

However, some studies indicate that the sexual differentiation of speciesspecific songs is not a straightforward developmental process. Interestingly, one early report noted that subadult male gibbons atypically sing some parts of female-specific songs in the species Nomascus concolor (Schilling 1984). This observation might imply that immature male gibbons are potentially able to sing some parts of female-specific songs, and suggests that both males and females develop common acoustic characteristics during the developmental process of song sexual differentiation, including female-specific patterns, with such female patterns disappearing in males after sexual maturation. This developmental scenario would challenge traditional views of sexual differentiation in the vocal behavior of gibbons and primates in general. The anecdotal nature of this previous report makes it difficult to evaluate, and in this paper, we report two observations of immature male gibbons from two different species, Hylobates agilis and Hylobates lar, spontaneously singing female-specific great calls. 
5/Koda et al. Video evidences for great calls by immature male gibbon

\section{Captive gibbon observations}

\section{Observational information}

\section{Subjects}

\section{Wild gibbon observations}

We observed one immature male of agile gibbon (H. agilis) in the wild and one immature male white-handed gibbon (H. lar) in captivity.

We investigated the behavior of wild agile gibbons in a tropical rainforest at the field station of Andalas University in Limau Manis ( $\left.0^{\circ} 54^{\prime} \mathrm{S}, 100^{\circ} 28^{\prime} \mathrm{E}\right)$, Sumatra, Indonesia, from August 23 to September 28, 2008. Field research was initiated at this site in 2004 (Koda et al. 2012; Oyakawa et al. 2007). The subject of this report was a 4- or 5-yearold immature male gibbon (named “Air”), belonging to B group, in the vicinity of the research station. The members of B group were habituated to human researchers and were individually identifiable. During the study period, we confirmed that B group contained an adult mated-pair, their presumed offspring (including the present subject) and a 1-year-old infant. The total time of field observations exceeded $227 \mathrm{~h}$ over $32 \mathrm{~d}$. 
6/Koda et al. Video evidences for great calls by immature male gibbon

Observations of a captive gibbon were made at the Japan Monkey Center, Inuyama, Aichi, Japan, on July 11, 2008. The subject was an immature male gibbon (named Bobby), who was born on August 5, 2003. At the time of observation, the gibbon was 5 years old. He was housed together with his family, i.e., his mother, 2-year-old brother and adult male.

\section{Results}

Observations of male great calls

Supplementary Video S1 is a video clip of Air co-singing with his mother (named “Gula”). Figure 1 shows a typical example sound spectrogram of a female-specific song, with great calls (Supplementary Sound S1). The great calls of agile gibbons are characterized by a sequential organization of multiple notes. Typically, at first, the great call is initiated with 2 or 3 notes of long duration (around $500 \mathrm{msec}$ ) and little frequency modulation. This is followed by a pitch-rising note with large frequency modulations (around $1200 \mathrm{~Hz}$ ). Finally, 2 or 3 high-pitched and loud notes are produced (Haimoff 1984; Oyakawa et al. 2007). We found that the acoustic structure of Air's song resemble female great calls. This observation provides direct evidence for the possibility that immature males also sing female-specific songs in agile gibbons. It would be interesting to determine whether this is a one-off observation, or if males routinely sing female songs. During 768 min of focused observation of the B group, we recorded the same immature male producing female-specific calls 21 times.

Similar to the observations of a male gibbon in the wild, we recorded the 
7/Koda et al. Video evidences for great calls by immature male gibbon vocalization of an immature male in captivity. Supplementary Video S2, S3, and S4 are video clips of an immature male (Bobby) co-singing with his mother. Each video clip contains singing events by Bobby. Based on the video clips, we confirmed that the acoustic characteristics of his singing were similar to female-specific great calls. In all 3 events, his mother always initiated the singing, and then Bobby also started to sing. The acoustic characteristics and sequential organization of white-handed gibbon songs are quite similar to those of agile gibbons. Typically, at first, the great call is initiated by 2 or 3 notes of long duration (around $500 \mathrm{msec}$ ), with little frequency modulations. Then, it is followed by a pitch-rising note with large frequency modulations (around $1200 \mathrm{~Hz}$ ). Finally, 2 or 3 high-pitched and loud notes are produced (Brockelman and Schilling 1984; Haimoff 1984; Geissmann 2002). Notes of long duration like those initiating great calls have not been previously reported in any types of male songs sung by whitehanded gibbons. Thus, it is usually easy to distinguish these sequential notes as the “introductory part” of great calls. Sound spectrograms of the 3 video clips (Figure 2) reveal that the immature male clearly emitted the long-duration notes, followed by the typical pitch-rising note. His movements during singing also mimicked those of females when giving great calls. Typically, females brachiate during and after producing great calls, and interestingly, the immature male also brachiated during the climax of his singing. Based on both the acoustic characteristics of his songs and his movements, it is reasonable to consider that this immature male sang great calls.

\section{Discussion}

Are our observations of male great calls “abnormal” behavior? 
8/Koda et al. Video evidences for great calls by immature male gibbon

Our observations clearly challenge the standard model for the development of great calls i.e., females acquire the ability to sing great calls as they mature, while males do not. However, a counter argument is that our observations were simply "exceptional” or "abnormal” might be plausible. Our observations from the wild group were obtained Successful recordings of male great calls from the captive subject were made on only one day, July 11, 2008. After making these recordings, we continued observations for one month, to confirm that the male gave great calls again; however, we failed to record great calls from this male subsequently. Interestingly, the keeper said that he had never heard any type of singing by this male prior to our observation, indicating that the great calls we recorded were the first time that this male had sung. Indeed, our observations of both wild and captive males are just case reports and might be interpreted as exceptions, instead of reflecting the species-typical behavior of male gibbons. More study is clearly needed before concluding that male gibbons habitually produce female great calls. Implications for the sexual differentiation of gibbon songs

So far, previous studies have reported that gibbon songs are sexually dimorphic; however, the developmental course of song acquisition remains unclear. 
9/Koda et al. Video evidences for great calls by immature male gibbon

Despite the obvious sex specificity in male and female songs, few data exist regarding the development of song. Based on the observations presented here, we speculate that additional study of song development will reveal more immature males giving great calls. Alternatively, it may be premature to generalize from the findings presented here. For example, we cannot overlook the fact that there have been no previous reports of male gibbons producing great calls, even though many captive gibbons have been housed in zoos throughout the world and gibbons have been the subjects of considerable research in the wild. Therefore, our observations may be anomalous. Unfortunately, it is unclear why the two immature males observed in this study gave great calls.

One possibility might be related to the idea that the great calls of mothers are a kind of "trigger" for the emergence of songs by their offspring. Recently, we reported the overlapping duets between mothers and their subadult daughters, where daughters acquired the acoustic features of her mothers' great calls and routinely co-sang with their them (Koda et al. 2013). Subadult daughters co-sang great calls with their mothers just before dispersing from the family group to form a new pair. Mother-daughter duets (interactions) are routinely observed, with daughters rarely singing without any overlap with the mother's great call. Here, we hypothesize that the great calls of mothers trigger their offspring to start the song when offspring just starts to produce sounds like song, even if the offspring is a son. Regardless of gender, offspring would first start to vocalize his/her songs together with the mother's great call. Great calls might serve as a trigger to motivate offspring to start the singing. If male androgen levels are not yet elevated in immature male offspring, they might start to give great calls. Once androgen levels begin to increase, the female-like features of great calls might diminish and switch to a male-specific song. This model is consistent with evidence from the video 
10/Koda et al. Video evidences for great calls by immature male gibbon

201

202

203

204

205

206 footage that appear to suggest that maternal great calls trigger offspring "singing." Careful observation of supplementary video S2 shows a very immature offspring hugging his mother rhythmically, while producing high-pitched screams that overlap with his mother's great call. The published literature also documents observations of an immature baby emitting screams while the mother sings her great calls (Preuschoft et al. 1984). Female great calls might play a role in triggering the onset of songs by offspring. Our observation of great calls by immature males might be a result of a maternal influence on song acquisition.

In sum, gibbon songs present a promising model for examining the developmental course of sexual dimorphism in behavior. Given that primates, including humans, rarely show clear sex-specific behavior, gibbon song would provide an ideal model system to investigate development and its endocrine basis. Future research should track how song changes in relation to hormonal states of singers. Such information could be used to study the development of sexual differentiation in primate vocal behavior. 
11/Koda et al. Video evidences for great calls by immature male gibbon

\section{Acknowledgements}

We thank Akira Kato, Jun Koike, Yuji Takenoshita, Koichiro Zamma, Takahisa Matsusaka, Noriko Ito, and all staff of the Japan Monkey Center for permitting us to conduct this study and for their assistance. We are grateful to Syamsuardi, Santi Nurulkamilah, and the staff of Andalas University, and many friends in Indonesia for their tremendous support and friendship; and to John C. Mitani and Esther Clarke for their comments on our manuscripts. Our fieldwork was conducted under the Memorandum of Universities between KUPRI and UNAND. This study was supported by a Grant-in-Aid for overseas research (B) (20405016) to Hirohisa Hirai (HK joined as a co-PI), and by the Young Researcher Overseas Visits Program for the Vitalizing Brain Circulation from the Primate Research Institute, Kyoto University. 
12/Koda et al. Video evidences for great calls by immature male gibbon

\section{References}

Brockelman WY, Schilling D (1984) Inheritance of stereotyped gibbon calls. Nature 312:634-636

Geissmann T (2002) Duet-splitting and the evolution of gibbon songs. Biological Review 77:57-76

Haimoff E (1984) Acoustic and organizational features of gibbon songs. In: Preuschoft H, Chivers D, Brockelman WY, Creel N (eds) The lesser apes: evolutionary and behavioural biology. Edinburgh University Press, Edinburgh

Koda H, Lemasson A, Oyakawa C, Rizaldi, Pamungkas J, Masataka N (2013) Possible role of mother-daughter vocal interactions on the development of species-specific song in gibbons. PLoS ONE 8: e71432

Koda H, Oyakawa C, Nurulkamilah S, Rizaldi, Sugiura H, Bakar A, Masataka N. (2012) Male replacement and stability of territorial boundary in a group of agile gibbons (Hylobates agilis agilis) in west Sumatra, Indonesia. Primates 53:327-332.

Lappan S, Whittaker D (2009) The gibbons: new perspectives on small ape socioecology and population biology. In. Springer-Verlag, New York

Marshall J, Marshall E (1976) Gibbons and their territorial songs. Science 193:235-237

Marshall J, Sugardjito J (1986) Gibbon systematics. In: Swindler DR, Erwin J (eds) Comparative Primate Biology, vol 1. Alan R. Liss., New York, pp 137-185

Merker B, Cox C (1999) Development of the female great call in Hylobates gabriellae: A case study. Folia Primatologica 70:97-106

Oyakawa C, Koda H, Sugiura H (2007) Acoustic features contributing to the individuality of wild agile gibbon (Hylobates agilis agilis) songs. American Journal of Primatology 69:777-790

Preuschoft H, Chivers D, Brockelman WY, Creel N (1984) The lesser apes: evolutionary and behavioural biology. In. Edinburgh University Press, Edinburgh

Schilling D (1984) Song bouts and duetting in the concolor gibbon. In: Preuschoft H, Chivers D, Brockelman WY, Creel N (eds) The lesser apes: evolutionary and behavioural biology. Edinburgh University Press, Edinburgh, pp 390-403 
13/Koda et al. Video evidences for great calls by immature male gibbon

Figure legends

Figure 1

Sound spectrogram of male great calls by a wild agile immature male gibbon (Sound S1). The spectrograms were generated using fast Fourier transform (sound sampling frequency $8 \mathrm{kHz}$, frame length $30 \mathrm{~ms}$, Gaussian window, time step 1ms, frequency step $20 \mathrm{~Hz}, 40 \mathrm{~dB}$ dynamic range), by Praat ver 5.3.19, developed by Paul Boersma and David Weenick, which is freely available online from www.praat.org. The extracted pitch contours colored in orange and blue represent the mother and her male offspring, respectively.

Figure 2

Sound spectrogram of male great calls by a captive white-handed immature male gibbon with that of his mother, which are presented in Video S2 (A), S3 (B), and S4 (C). The extracted pitch contours colored in orange and blue represent the mother and her male offspring, respectively. 
14/Koda et al. Video evidences for great calls by immature male gibbon

\section{Legends for Supplementary video clips}

\section{Video S1}

A sample video clip of an immature male gibbon singing great calls in the wild. The larger gibbon was the mother, and smaller one was her son (Air). The two of them sang together in the canopy of a 20-meter-high tree. At the time of this video clip, the mother had already started to sing great calls, and Air had not previously begun to sing with her. After the mother had sung the great calls several times, Air also sang with her. As the great calls reached a climax, the two of them brachiated through the canopy of the forest. In this video, the mother moved first and was then followed by Air replicating her movements.

\section{Video S2}

This is the video clip in which we successfully filmed the first case of male great calls in captivity. At the time (11 ${ }^{\text {th }}$ July, 2008), we were filming gibbon singing for another purpose, so the video camera on the tripod was placed in front of the home cage, covering a wide view of the cage, not focusing on the immature male (Bobby). Bobby had a middle-sized body with black fur. The mother was a large gibbon with a brown and buff fur color, and the smallest gibbon with white fur was her 2-year-old son. The mother's male partner was not filmed, but his songs were recorded in this video. First, the mother sang the great calls alone. Just after the mother started to sing the great call, Bobby approached her closely. The 2-year-old son also approached her after Bobby. As the mother's great call reached its climax, Bobby also began to sing. The mother jumped from the branch to right side when singing the climax. Bobby also jumped to the left side while singing, following the mother's great call and jumping behavior. The 2-year-old son also jumped following the mother and Bobby.

\section{Video S3}

This video clip was made after Video S2. After watching Bobby's great call, we tried to film him at a closer distance. As in S2, the mother first started to sing a great call. As the mother's great call reached its climax, Bobby also joined in singing. In this case, the mother did not brachiate as much, while Bobby brachiated while singing his climax. Interestingly, the 2-year-old son approached the mother when she singing the climax part, and repeatedly called with very high pitch screaming. At the end of this video, the male partner (black fur) entered the film, but he did not join in the duet at that time. 
15/Koda et al. Video evidences for great calls by immature male gibbon

\section{Video S4}

The final observation was made after Video S3. In this case, when the mother started to sing, Bobby almost simultaneously started to sing with her. Bobby remained close to his mother during the early part of the singing. During their singing, the screams of the 2year-old son were sometimes heard too. At the climax part, only Bobby jumped in the cage. A short conversation in Japanese between the observer (HK) and the keeper is included in the video clip.

\section{Sound S1}

The typical example of an immature male gibbon singing great calls in the wild. The sound spectrogram was shown in Figure 1. 


\section{$10 \mathrm{sec}$}

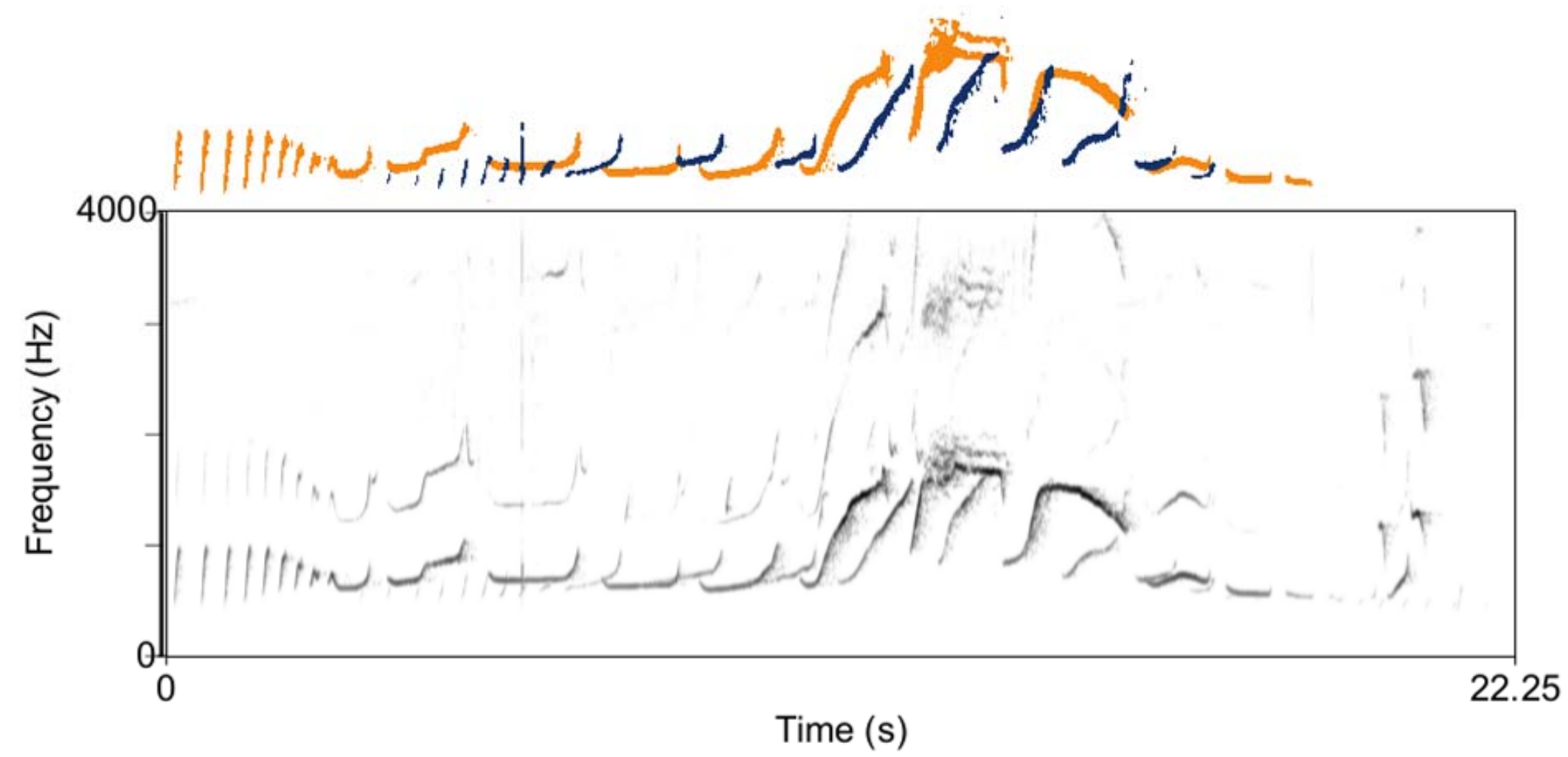

Figure 1 


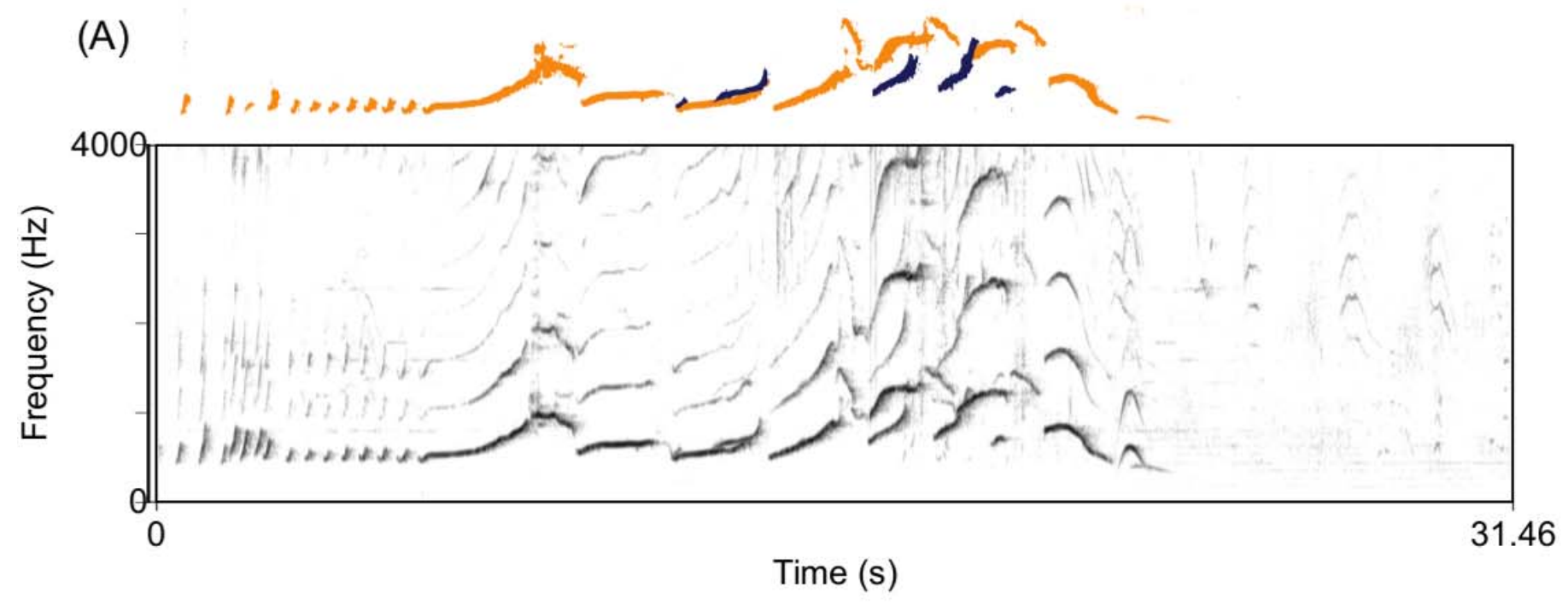

(B)
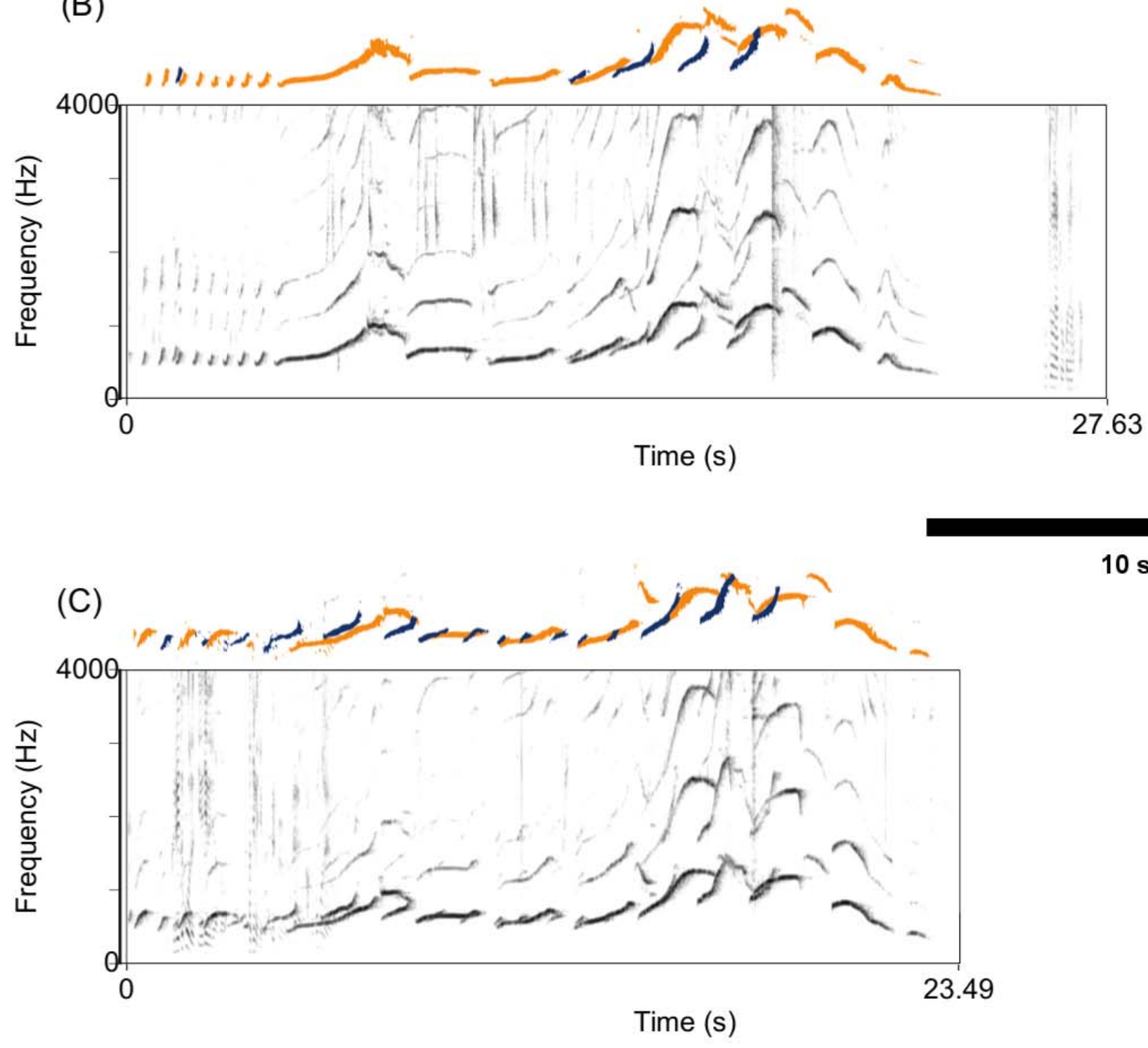

$10 \mathrm{sec}$

Figure 2 